\title{
Persistent hyperglycemia is a useful glycemic pattern to predict stroke mortality: a systematic review and meta-analysis
}

\author{
Duanlu Hou ${ }^{1}$, Ping Zhong ${ }^{2}$, Xiaofei $\mathrm{Ye}^{3}$ and Danhong Wu ${ }^{1^{*}}$ (D)
}

\begin{abstract}
Background: Glycemic patterns have been reported to be prognostic factors for stroke; however, this remains to be further evaluated. This meta-analysis aimed to evaluate the usefulness of glycemic patterns such as persistent hyperglycemia (PH) including short duration and long duration PH (SPH; LPH), admission hyperglycemia (AH), short-duration hyperglycemia (SH), and persistent normoglycemia (PN) in predicting stroke prognosis using published results.

Methods: Major scientific databases including but are not limited to PubMed, EMBASE, Web of Science, Ovid, CNKI (Chinese National Knowledge Infrastructure), and Clinicaltrials.gov were searched till 1st March 2021 for clinical trials on the correlation between glycemic patterns and stroke outcomes. The primary outcome was defined as short-term (1- or 3-month) post-stroke mortality, and the secondary outcome was post-stroke hemorrhage at 6 months.
\end{abstract}

Results: Ten studies involving 3584 individuals were included in the final analysis. In subgroup analyses, PH patients with no history of diabetes had increased post-stroke mortality (odds ratio [OR]: 4.80, 95\% Cl: 3.06-7.54) than patients with no $\mathrm{PH}$; and patients with glucose levels $>140 \mathrm{mg} / \mathrm{dl}$ had greater mortality (OR: 5.12, 95\% Cl: 3.21-8.18) than those with glucose levels $<140 \mathrm{mg} / \mathrm{dl}$; compared with AH patients, $\mathrm{PH}$ patients had increased short-term mortality (OR: $0.31,95 \% \mathrm{Cl}: 0.16-0.60)$. In the prediction of stroke mortality among patients without diabetes, SPH (OR: 0.28 , 95\%Cl: 0.12-0.69) seemed to be more related to increased mortality than LPH (OR: 0.35, 95\% Cl: 0.14--0.90).

Conclusions: $\mathrm{PH}$, especially SPH, could predict increased post-stroke mortality in non-diabetic patients. The rank of individual glycemic patterns in predicting stroke mortality in non-diabetic patients was $\mathrm{SPH}>\mathrm{LPH}>\mathrm{AH}>\mathrm{PN}$.

Keywords: Persistent hyperglycemia, Stroke, Mortality, meta-analysis

\section{Background}

Stroke, especially ischemic stroke, has a high incidence of mortality and morbidity [1]. Many factors, such as age, National Institutes of Health Stroke Scale (NIHSS) score at admission, infarct size, history of diabetes mellitus (DM), hypertension, and blood glucose level, have been used to predict short-term post-stroke mortality [2,3]. A higher blood glucose level at admission predicts worse

\footnotetext{
*Correspondence: danhongwu@fudan.edu.cn

1 Department of Neurology, Shanghai Fifth People's Hospital, Fudan

University, 801 Heqing Road, Minhang District, Shanghai 200240, China

Full list of author information is available at the end of the article
}

short-term stroke outcomes, such as increased mortality and hemorrhagic transformation (HT) in patients with ischemic stroke [4-7]. Persistent hyperglycemia ( $\mathrm{PH})$, defined as a hyperglycemic state with blood glucose levels $>140$ or $150 \mathrm{mg} / \mathrm{dl}$ measured at admission and at a random time point within a duration ( $\geq 24 \mathrm{~h}$, i.e., $48-72 \mathrm{~h}$ [8]) since admission $[9,10]$, can predict poor functional outcomes and increased HTs in patients with stroke with or without DM $[9,10]$. In addition, $\mathrm{PH}$ can be divided into two subgroups: short duration $\mathrm{PH}(\mathrm{SPH})$ and longduration PH (LPH); SPH is defined as a high glucose status at the time of admission and at a random time after 
admission, with the random time after admission being within $24 \mathrm{~h}$ after admission, and LPH is defined as a high glucose status at the time of admission and at a random time after admission, with the random time after admission being greater than $24 \mathrm{~h}$ after admission. However, other studies found no significant difference in this prediction between persistent hyperglycemic and normoglycemic states in patients with stroke $[8,11]$. Hyperglycemia of long duration (more than $1 \mathrm{~d}$ after admission) can better predict worse stroke outcomes than a singlepoint hyperglycemia after stroke onset $(\mathrm{SH}$, defined as hyperglycemia only at $24 \mathrm{~h}$ after stroke onset) $[9,10]$ ) or at admission $(\mathrm{AH}$, which was defined as hyperglycemia at admission) [8, 10, 12-14]. Apart from the studies mentioned above, few studies have investigated the efficacy of $\mathrm{PH}, \mathrm{AH}$, and $\mathrm{SH}$ in predicting post-stroke outcomes, and the superiority of $\mathrm{PH}$ over $\mathrm{SH}$ and $\mathrm{AH}$. This metaanalysis aimed to answer this question by summarizing currently available results on the efficacy of $\mathrm{PH}, \mathrm{AH}$, and $\mathrm{SH}$ in predicting stroke outcomes, which will contribute to the selection of treatments to improve post-stroke prognosis.

\section{Methods}

\section{Literature search}

This study was reported following the Preferred Reporting Items for a Systematic Review and Meta-analysis (PRISMA) [15] and Meta-analysis of Observational Studies in Epidemiology (MOOSE) [16] guidelines (see Supplemental Materials). PubMed, Embase, Web of Science, Ovid, China National Knowledge Infrastructure, and ClinicalTrials. gov were searched for relevant studies published or registered before March 1, 2021. Studies on the correlation between hyperglycemia, especially persistent hyperglycemia, and stroke outcomes were included for further analysis. Key words used for searching included persistent hyperglycemia (such as "persistent hyperglycemia" or "hyperglycemia"), admission hyperglycemia (such as "hyperglycemia at admission" or "admission hyperglycemia") were combined with key terms related to stroke outcomes (such as "stroke outcomes" or "stroke prognosis"). No language restrictions were imposed. The exact search strategy and rationale are shown in Supplementary file 1. Additional articles were obtained from the reference lists of the articles identified in the initial search.

\section{Selection criteria}

The inclusion criteria were as follows: 1) cohort, casecontrol, and cross-sectional studies including unpublished studies that focused on correlations between $\mathrm{AH}$, $\mathrm{SH}, \mathrm{PH}, \mathrm{PN}$, and stroke outcomes, and must include $\mathrm{PH}$; 2) stroke (ischemic and hemorrhagic stroke) must be well confirmed on either magnetic resonance imaging or computed tomography. Exclusion criteria included: 1) studies without a clear definition of outcomes (i.e., mortality and HT) or glycemic patterns; 2) studies aimed at insulin therapy or other therapies, or glucose monitoring for stroke patients with abnormal glucose levels; 3) studies, including unpublished studies, lacking sufficient data for analysis. Cohort, case-control, and cross-sectional studies that examined the correlation between blood glucose levels and stroke were included for further analysis. Two reviewers (D Hou and D Wu) independently reviewed the title, abstract, and full text of each article, and details of their results were entered into a data extraction form. A third reviewer ( $\mathrm{P}$ Zhong) checked and approved the study. When data were missing, the corresponding authors of those studies were contacted through e-mail for further information (mainly by D Hou). If the corresponding author could not provide the missing data, the study was excluded. The primary outcome was 30 -day or 3 -month mortality (or $\mathrm{mRS}=6$ ) of patients with stroke belonging to the four glycemic patterns, namely $\mathrm{AH}, \mathrm{SH}$, $\mathrm{PH}$, and persistent normoglycemia $(\mathrm{PN})$. The secondary outcome was HT or re-bleeding at 6 months.

\section{Data extraction}

Two investigators independently extracted the data and entered them into the data extraction form. The following information was recorded: the first author, publishing date, study design/study name, geographical location, population/ethnicity, time of baseline survey, sample population, definition, sample size, sex, summary statistics (using a standardized extraction form), and degree of adjustment for potential confounders (Table 1).

\section{Quality assessment}

Study quality was evaluated using the Newcastle-Ottawa Scale (NOS) for cohort and case-control studies (see Supplemental Materials). The quality of studies was determined by examining their compliance to the selection criteria, comparability of cases and controls, exposure, and outcome assessments. For cross-sectional studies, quality was assessed using the NOS modified for this type of study [19]. Overall, a score of $\geq 5$ indicated adequate quality for inclusion in this meta-analysis.

\section{Statistical analysis}

The primary and secondary outcomes of the included studies were analyzed as categorical variables with the effectiveness of different treatments evaluated and interpreted with a summary odds ratio (OR) and their corresponding 95\% confidence intervals (CI). Classic $\chi^{2}$ test, $\mathrm{Q}^{2}$, and $\mathrm{I}^{2}$ statistics were used to assess the magnitude of heterogeneity between the studies. The significance 


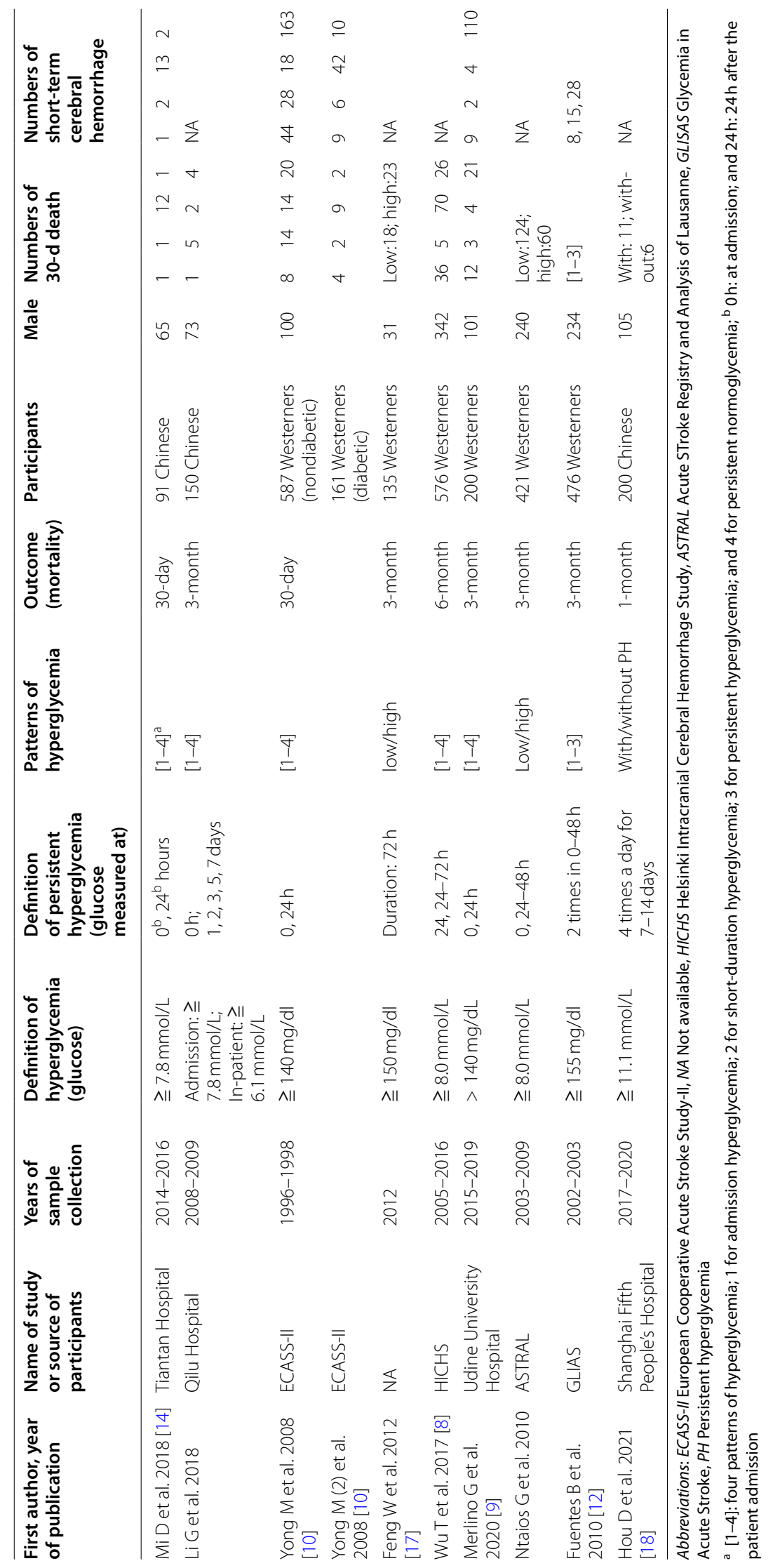


level was set at $P<0.05$. In the analysis, a random-effects model was used. We assumed a priori that the metaanalysis could be affected by the variance between studies due to the different inclusion criteria, which is more appropriately addressed by a random-effect model rather than a fixed-effect model. Inverted funnel plots were used to assess the potential presence of a publication bias. All data analyses were conducted and verified using Review Manager 5.4 (Cochrane Collaboration, Oxford, UK) and Stata/SE 15.0 (Stata Corp., USA).

\section{Patients enrollment of the cohort study in Shanghai (or Hou et al., 2021)}

Consecutive patients with either ischemic or hemorrhagic stroke were screened and selected from the Stroke Unit of Shanghai Fifth People's Hospital between April 1, 2017, and February 1, 2020. The inclusion and exclusion criteria were the same as those reported in a previous study (see Supplemental materials) [18].

\section{Data availability}

Details of anonymized data will be available to any qualified investigators.

\section{Results}

The initial search found 85 articles in the databases with one additional single-centered study showing negative results on $\mathrm{PH}$ for stroke outcomes (the study was included after quality evaluation, NOS 7 stars) (Table S1), which is shown in the Supplementary file (Table S1, Hou, et al., 2021). The main findings and comparisons of the Shanghai study are shown in the Supplementary materials, named as a suffix: Hou et al., 2021). After carefully reading the abstracts and titles by Hou and Wu, 28 records were retained. Seventeen studies were excluded because their titles or abstracts did not meet the inclusion criteria. One was excluded because no detailed data were available. Full texts of 10 records $[8-12,14,17,20$, 21] (one study [10] was regarded as two records because it included two groups of the population, one was on DM

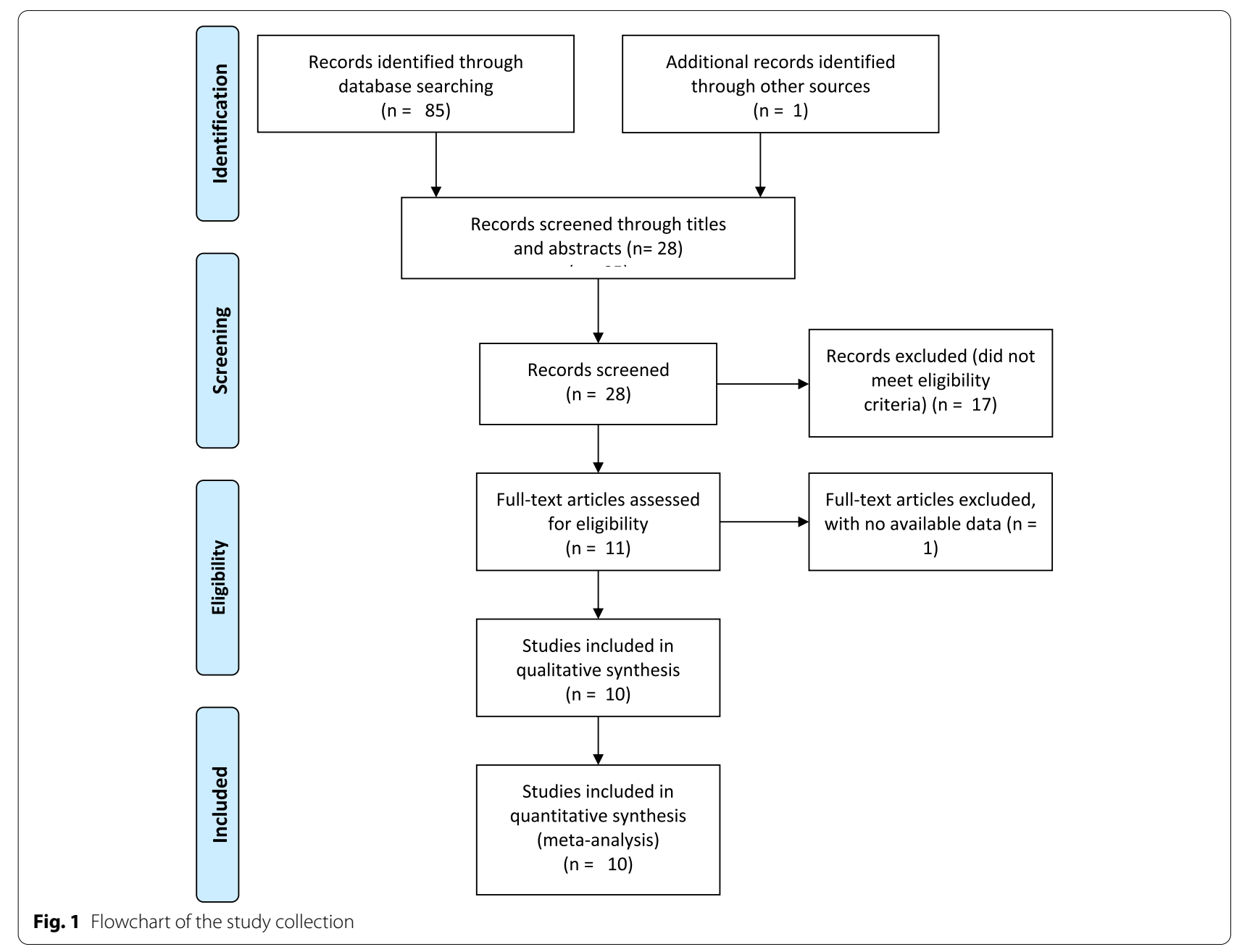


patients and the other on non-DM patients) were carefully evaluated by Dr. Hou, Wu, and Zhong. A total of 3584 patients were included in the final meta-analysis, as shown in Fig. 1 and Table 1.

\section{Overall comparisons of the primary and secondary outcomes between $\mathrm{PH}$ and non- $\mathrm{PH}, \mathrm{AH}$ and non-AH, $\mathrm{SH}$ and non-SH, and PN and non-PN patients: a need for subgroup analysis}

The correlation between $\mathrm{AH}, \mathrm{SH}, \mathrm{PH}$, or $\mathrm{PN}$ and stroke outcomes is shown in Fig. 2. In 10 cohort studies, 3275 patients were included to assess the correlation between the primary outcome and $\mathrm{PH}$ in both $\mathrm{PH}$ and non- $\mathrm{PH}$ patients (Fig. 2A). Compared with $\mathrm{PH}$ patients, non-PH patients tended to have lower mortality (OR: $3.68,95 \%$ CI 2.30-5.89), which seemed to have a protective role. However, there was significant heterogeneity among these studies $\left(\mathrm{I}^{2}=78 \%, P<0.00001\right)$. We then removed the data from Yong from the original analysis and performed the statistical analysis again (Fig. S4), and found that the heterogeneity of the data did not decrease significantly $\left(\mathrm{I}^{2}=0.69, P=0.003\right)$, which suggests that the determining factor leading to heterogeneity is not the presence or absence of the study by Yong (2008), but probably the different internal design of each study. In three cohort studies, 1079 patients were included to assess the correlation between $\mathrm{PH}$ and the secondary outcome in both $\mathrm{PH}$ and non-PH patients (Fig. $2 \mathrm{~B}$ ) with significant heterogeneity $\left(\mathrm{I}^{2}=80 \%, P=0.002\right)$. When the correlation between short-term mortality, hemorrhagic rate, and $\mathrm{AH}$ or $\mathrm{SH}$ was analyzed, no significant difference in short-term mortality or hemorrhagic rate was found between $\mathrm{AH}$ and non- $\mathrm{AH}$ patients, or between $\mathrm{SH}$ and non-SH patients (Fig. 2C-D). In contrast, a negative correlation was found between PN and mortality as well as hemorrhage (OR: $2.83,95 \%$ CI: $1.83-4.40$ for mortality, $\mathrm{I}^{2}=0.63, P=0.009$; OR: $1.73,95 \%$ CI: $1.03-2.90$ for hemorrhage, $\mathrm{I}^{2}=0.43, P=0.15$ ).

\section{Subgroup analysis of the correlations in DM or non-DM patients: primary and secondary outcomes}

Based on the characteristics of the included studies, we grouped them based on a number of variables (i.e., presence of $\mathrm{DM}$, duration of $\mathrm{PH}$, and different definitions of hyperglycemia). It was found that $\mathrm{PH}$ was positively correlated with adverse outcomes (i.e., death) in stroke patients without a history of DM (OR: 4.80, 95\% CI: 3.06-7.54) compared with patients without PH. The heterogeneity of these studies was relatively small $\left(\mathrm{I}^{2}=24 \%, P=0.27\right)$. These results suggest that the presence or absence of DM is a particularly critical confounding factor that affects the efficacy of $\mathrm{PH}$ in predicting post-stroke mortality. In four studies, 249 patients were included to assess the correlation between $\mathrm{AH}$ or $\mathrm{PH}$ and primary outcomes (Fig. 3.1.1). It was found that $\mathrm{AH}$ patients had lower post-stroke mortality (OR: $0.31,95 \%$ CI: 0.16-0.60) than PH patients in those without DM, whereas no significant difference was found in patients with DM (Fig. 3.1.2), suggesting that PH had a significant impact on stroke outcome in non-diabetic patients. Short duration $(<24 \mathrm{~h})$ of $\mathrm{PH}$ or SPH was correlated with higher stroke mortality (OR: $0.28,95 \%$ CI: $0.12-0.69$ ) than long duration $(>24 \mathrm{~h})$ of PH or LPH (OR: $0.35,95 \% \mathrm{CI}$ : $0.14-0.90)$ in stroke patients without DM. Both SPH and $\mathrm{LPH}$ were better than $\mathrm{AH}$ in predicting stroke mortality. Therefore, the rank of the efficacy of glycemic patterns in predicting stroke mortality in nondiabetic patients was $\mathrm{SPH}>\mathrm{LPH}>\mathrm{AH}>\mathrm{PN}$.

In four studies, 857 patients were included to assess the correlation between $\mathrm{AH}$ or PN and primary outcomes (Fig. 4). No heterogeneity was found between these studies $\left(\mathrm{I}^{2}=0 \%, P=0.59\right)$, and $\mathrm{PN}$ patients had the lower post-stroke mortality (OR: 2.04, 95\% CI: 1.15-3.63) than $\mathrm{AH}$ patients in those without DM.

\section{Subgroup analysis of the correlations in patients with $\mathrm{PH}<24 \mathrm{~h}$ vs $>24 \mathrm{~h}$}

In addition, $\mathrm{PH}<24 \mathrm{~h}$ led to increased stroke mortality (OR: 6.71, 95\%CI: 3.58-12.57) compared with $\mathrm{PH}>24 \mathrm{~h}$ (OR: 3.35, 95\% CI: 1.75-6.43) in non-diabetic stroke patients. It seemed that a short duration of $24 \mathrm{~h}$ of $\mathrm{PH}$ was better at predicting post-stroke mortality than a long duration of PH (Fig. 5).

\section{Subgroup analysis of the correlations in patients with glucose levels $>140$ or $150 \mathrm{mg} / \mathrm{dl}$}

Furthermore, the total OR for post-stroke mortality was 5.12 (95\% CI: 3.21-8.18) in non-PH patients with glucose (GLC) levels $>140 \mathrm{mg} / \mathrm{dl}(7.8 \mathrm{mmol} / \mathrm{L})$, and no heterogeneity was found $\left(\mathrm{I}^{2}=3 \%, P=0.38\right)$. However, the OR was 2.90 (95\% CI: $2.25-3.74)$ in non-PH patients with GLC levels $>150 \mathrm{mg} / \mathrm{dl}$, and significant heterogeneity was present. It is clear from the analysis here that caution is needed in defining hyperglycemia because a higher threshold of glucose level may lose patients who should be actively treated to gain favorable outcomes. (Fig. 5).

\section{Publication bias and Egger's test}

Results of the Egger's test for mortality between PH and non-PH groups $(P=0.584)$ in the general population, between the $\mathrm{PH}$ and non-PH groups without $\mathrm{DM}$ $(P=0.419)$, between the $\mathrm{AH}$ and $\mathrm{PH}$ groups without 


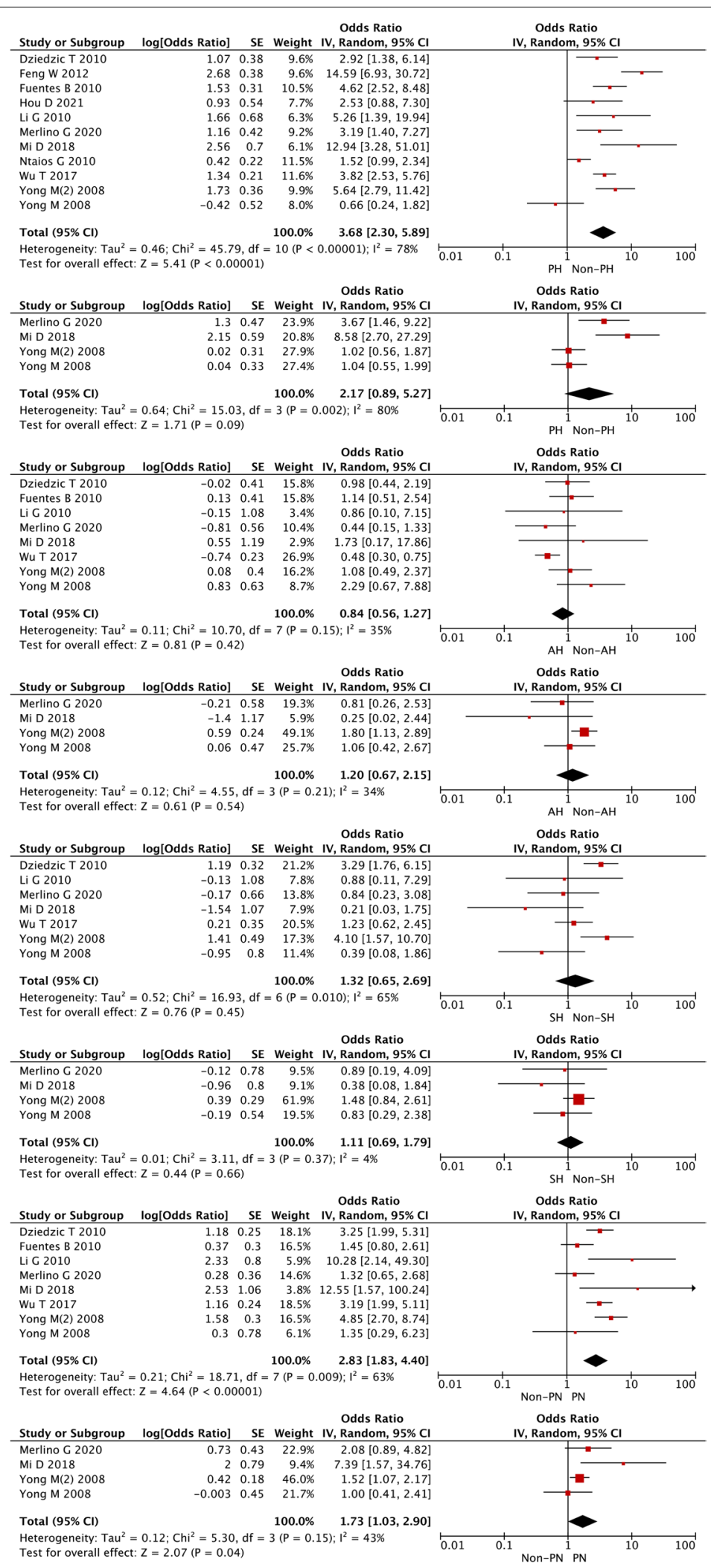

Fig. 2 Forest plots of $\mathrm{PH}, \mathrm{AH}, \mathrm{SH}$, non-PN for poststroke mortality $(\mathbf{A}, \mathbf{C}, \mathbf{E}, \mathbf{G})$, and poststroke hemorrhage prediction (B, D, F, H) 


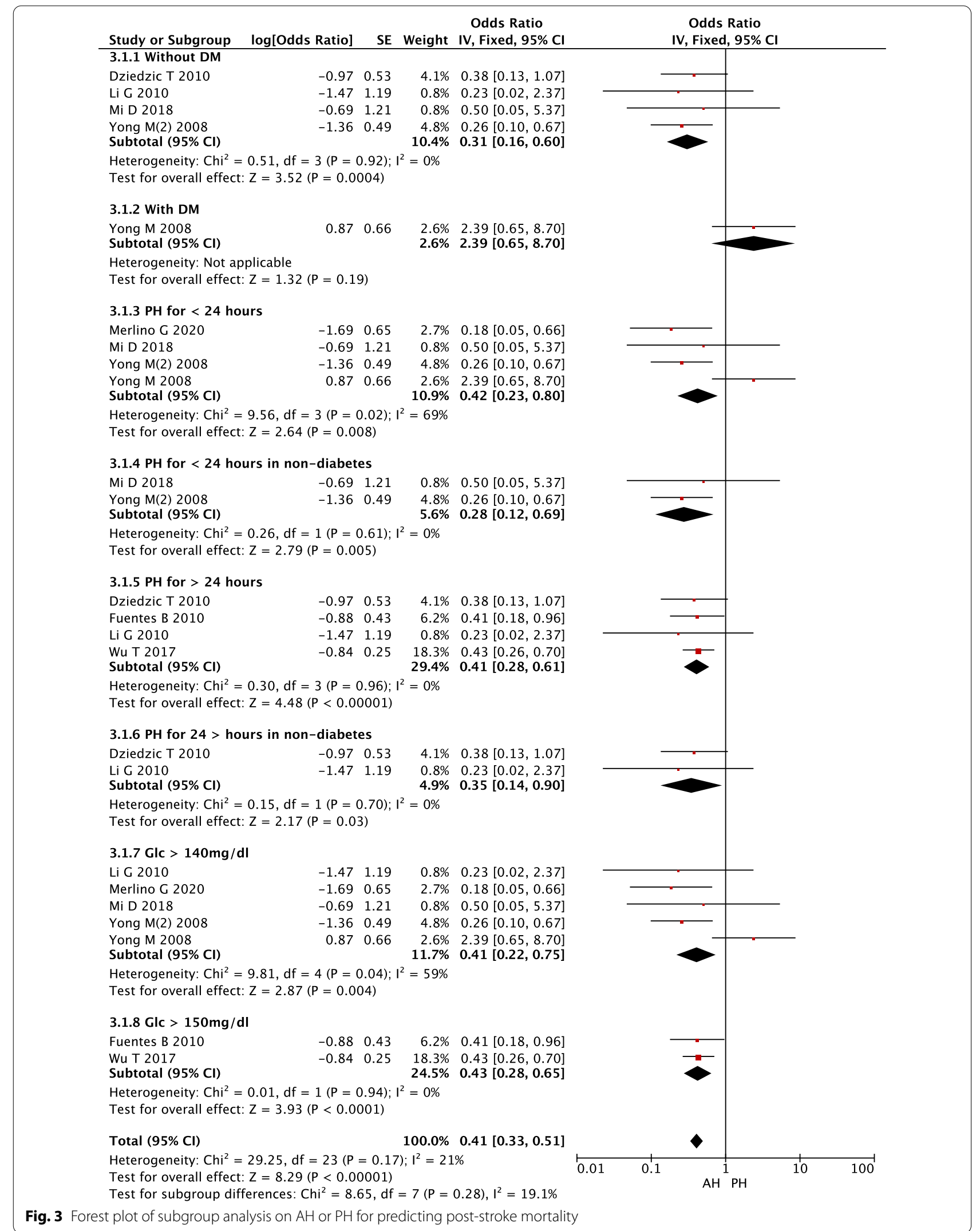




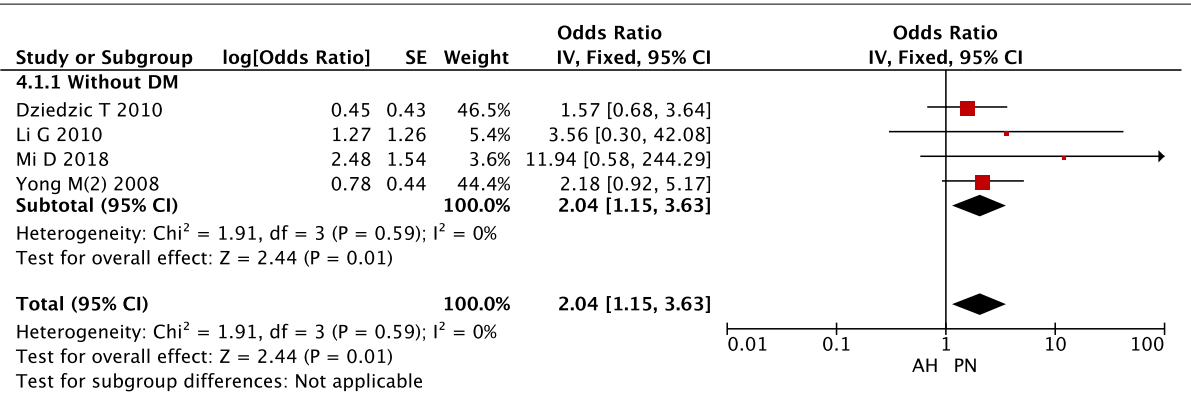

Fig. 4 Forest plot of subgroup analysis on AH or PN for predicting post-stroke mortality

DM $(P=0.888)$, and mortality between the AH and PN groups without DM $(P=0.418)$ suggested that no publication bias was found among the included studies (Fig. 6 for two main subgroup analyses, Fig. S1, and Fig. S2, Egger).

\section{Discussion}

This study analyzed the correlation between hyperglycemic patterns and stroke mortality. It was found that $\mathrm{PH}$ could predict worse stroke outcomes in non-diabetic patients. The efficacy of glycemic patterns in predicting poor stroke outcomes in nondiabetic patients was ranked as $\mathrm{SPH}>\mathrm{LPH}>\mathrm{AH}>\mathrm{PN}$. No conclusion on $\mathrm{SH}$ was reached owing to the lack of sufficient studies for analysis. The presence of DM is an important confounder. In populations with DM, heterogeneity was observed, and no difference was found in the efficacy of glycemic patterns in predicting stroke mortality and their ranking (details are shown in the Results section).

Over $50 \%$ of patients within each stroke subtype had glucose levels greater than $6.0 \mathrm{mmol} / \mathrm{l}$ on admission [22]. Post-stroke hyperglycemia not only worsens functional outcomes and vascular perfusion [23], but also leads to spontaneous intracerebral hemorrhage, impaired executive functions [24], and death [25] in stroke patients, especially in patients with large vessel occlusion $[26,27]$. Blood glucose levels seem to decline within the first $24 \mathrm{~h}$ after stroke onset [28], but they rise again after approximately $24-88 \mathrm{~h}$, regardless of the presence of DM $[29,30]$. $\mathrm{PH}$ with high blood glucose levels lasting for $24 \mathrm{~h}$ or more seems to have a controversial effect on stroke outcomes $[11,13]$, which requires further analysis to confirm the efficacy of different glycemic patterns in predicting poststroke mortality. The overall analysis of the general population with stroke showed a significant difference that $\mathrm{PH}$ patients had increased post-stroke mortality than non$\mathrm{PH}$ patients and a trend that PN patients had decreased post-stroke mortality and hemorrhagic rate than non-PN patients.
A systematic review [31] found that acute hyperglycemia predicts an increased risk of in-hospital mortality after ischemic stroke in non-diabetic patients and an increased risk of poor functional recovery in non-diabetic stroke survivors, which implies the impact of high glucose levels on stroke mortality. Thus, hyperglycemic status in non-diabetic patients is more closely related to the prognosis of ischemic stroke. There are a couple of reasons for the low prognostic efficacy of $\mathrm{AH}$ and $\mathrm{PH}$ in patients with DM. First, there are many confounding factors, including the presence of multiple complications (such as kidney and heart diseases) [32] and glucoselowering therapies in elderly people with long-term DM (mainly type $2 \mathrm{DM}$ ), that influence the prognostic efficacy. Second, the super-chronic mild hyperglycemic state (in which blood glucose levels are not that high due to the effect of glucose-lowering drugs) does not have a significant impact on the short-term prognosis; instead, this life-long mild hyperglycemic state might affect outcomes decades later.

A correlation between stress hyperglycemia and vascular damage has also been reported [31]. Hyperglycemia was unable to predict stroke mortality independently. However, when NIHSS was removed from the multivariate model, stress hyperglycemia became an independent predictor of in-hospital mortality along with age, atrial fibrillation (AF), diastolic blood pressure (DBP), and logtriglyceride (TG) levels [33]. This suggests that hyperglycemia in non-diabetic patients reflects the severity of stroke. It is hypothesized that $\mathrm{AH}$ or stress hyperglycemia due to the release of stress hormones by the nervous system [34] may be a marker of stroke severity. The possible underlying mechanism is that a high level of glucose in the brain leads to cell death through the activation of hexokinase II $[35,36]$. The negative correlation observed in the present study might be due to the difference in the definition of hyperglycemia (i.e., $126 \mathrm{mg} / \mathrm{dl}$, not $140 \mathrm{mg} /$ dl). Among the included studies, some included populations with the same disease severity $[9,10]$, and some studies included patients with slightly higher NIHSS 
Odds Ratio

Odds Ratio

$\begin{array}{llll}\text { Study or Subgroup } & \text { log[Odds Ratio] } & \text { SE Weight } & \text { IV, Fixed, } 95 \% \mathrm{CI}\end{array}$

5.1.1 Without DM

$\begin{array}{llll}1.07 & 0.38 & 3.0 \% & 2.92[1.38,6.14]\end{array}$

Li G 2010

$\begin{array}{llll}1.66 & 0.68 & 0.9 \% & 5.26[1.39,19.94]\end{array}$

Mi D 2018

$\begin{array}{llll}2.56 & 0.7 & 0.9 \% & 12.94[3.28,51.01]\end{array}$

Yong M(2) 2008

$\begin{array}{llll}1.73 & 0.36 & 3.3 \% & 5.64[2.79,11.42\end{array}$

Subtotal $(95 \% \mathrm{Cl})$

$8.1 \% \quad 4.64[2.79,1.42]$

Heterogeneity: $\mathrm{Chi}^{2}=3.95, \mathrm{df}=3(\mathrm{P}=0.27) ; \mathrm{I}^{2}=24 \%$

Test for overall effect: $Z=6.81(P<0.00001)$

\subsubsection{With DM}

$\begin{array}{lllll}\text { Ntaios G } 2010 & 0.42 & 0.22 & 8.9 \% & 1.52[0.99,2.34]\end{array}$

$\begin{array}{lllll}\text { Yong M } 2008 & -0.42 & 0.52 & 1.6 \% & 0.66[0.24,1.82\end{array}$

$\begin{array}{lll}\text { Subtotal }(95 \% \mathrm{Cl}) & 10.5 \% & 1.34[0.90,1.99]\end{array}$

Heterogeneity: $\mathrm{Chi}^{2}=2.21, \mathrm{df}=1(\mathrm{P}=0.14) ; \mathrm{I}^{2}=55 \%$

Test for overall effect: $Z=1.44(P=0.15)$

5.1.3 PH for $<24$ hours

\begin{tabular}{|c|c|c|c|c|}
\hline Merlino G 2020 & 1.16 & 0.42 & $2.5 \%$ & $3.19[1.40,7.27]$ \\
\hline Mi D 2018 & 2.56 & 0.7 & $0.9 \%$ & $12.94[3.28,51.01]$ \\
\hline Yong M(2) 2008 & 1.73 & 0.36 & $3.3 \%$ & $5.64[2.79,11.42]$ \\
\hline $\begin{array}{l}\text { Yong M } 2008 \\
\text { Subtotal }(95 \% \mathrm{Cl})\end{array}$ & -0.42 & 0.52 & $\begin{array}{l}1.6 \% \\
8.3 \%\end{array}$ & $\begin{array}{l}0.66[0.24,1.82] \\
3.43[2.19,5.38]\end{array}$ \\
\hline
\end{tabular}

5.1.4 PH for $<24$ hours in non-diabetes

$\begin{array}{lllll}\text { Mi D } 2018 & 2.56 & 0.7 & 0.9 \% & 12.94[3.28,51.01]\end{array}$

$\begin{array}{lllll}\text { Yong M(2) } 2008 & 1.73 & 0.36 & 3.3 \% & 5.64[2.79,11.42]\end{array}$

$\begin{array}{rl}4.2 \% & 6.71[3.58,12.57]\end{array}$

Heterogeneity: $\mathrm{Chi}^{2}=1.11, \mathrm{df}=1(\mathrm{P}=0.29) ; \mathrm{I}^{2}=10 \%$

Test for overall effect: $Z=5.95(P<0.00001)$

5.1.5 PH for $>24$ hours

Dziedzic T 2010

Feng W 2012

Fuentes B 2010

Hou D 2021

Li G 2010

Ntaios G 2010

Wu T 2017

Subtotal $(95 \% \mathrm{Cl})$

$\begin{array}{rrr}1.07 & 0.38 & 3.0 \% \\ 1.43 & 0.4 & 2.7 \%\end{array}$

$\begin{array}{lll}1.53 & 0.31 & 4.5 \%\end{array}$

$\begin{array}{lll}0.93 & 0.54 & 1.5 \%\end{array}$

$\begin{array}{lll}1.66 & 0.68 & 0.9 \%\end{array}$

$\begin{array}{lll}0.42 & 0.22 \quad 8.9 \%\end{array}$

$\begin{array}{lll}1.34 & 0.21 \quad 9.8 \%\end{array}$

$31.4 \%$

Heterogeneity: $\mathrm{Chi}^{2}=14.21, \mathrm{df}=6(\mathrm{P}=0.03) ; \mathrm{I}^{2}=58 \%$

Test for overall effect: $Z=9.17(P<0.00001)$

5.1.6 $\mathrm{PH}$ for $>24$ hours in non-diabetes

$\begin{array}{lllrr}\text { Dziedzic T } 2010 & 1.07 & 0.38 & 3.0 \% & 2.92[1.38,6.14] \\ \text { Li G } 2010 & 1.66 & 0.68 & 0.9 \% & 5.26[1.39,19.94]\end{array}$

Li G $2010 \quad 1.66 \quad 0.68 \quad 0.9 \% \quad 5.26[1.39,19.94]$

Subtotal $(95 \% \mathrm{Cl})$

$3.35[1.75,6.43]$

Test for overall effect: $Z=3.65(P=0.0003)$

5.1.7 Glc $>140 \mathrm{mg} / \mathrm{dl}$

$\begin{array}{lrrrr}\text { Feng W 2012 } & 1.66 & 0.68 & 0.9 \% & 5.26[1.39,19.94] \\ \text { Fuentes B 2010 } & 1.16 & 0.42 & 2.5 \% & 3.19[1.40,7.27] \\ \text { Ntaios C 2010 } & 2.56 & 0.7 & 0.9 \% & 12.94[3.28,51.01] \\ \text { Wu T 2017 } & 1.73 & 0.36 & 3.3 \% & 5.64[2.79,11.42] \\ \text { Subtotal (95\% CI) } & & & \mathbf{7 . 6 \%} & \mathbf{5 . 1 2}[3.21,8.18]\end{array}$

Subtotal $(95 \% \mathrm{Cl})$

Heterogeneity: $\mathrm{Chi}^{2}=3.10, \mathrm{df}=3(\mathrm{P}=0.38) ; \mathrm{I}^{2}=3 \%$

Test for overall effect: $Z=6.85(P<0.00001)$

$5.1 .8 \mathrm{Glc}>150 \mathrm{mg} / \mathrm{dl}$

Feng W 2012

Fuentes B 2010

Ntaios G 2010

Wu T 2017

Subtotal $(95 \% \mathrm{Cl})$

$\begin{array}{lll}1.43 & 0.4 & 2.7 \%\end{array}$

$\begin{array}{lll}1.53 & 0.31 & 4.5 \%\end{array}$

$\begin{array}{lll}0.42 & 0.22 \quad 8.9 \%\end{array}$

$\begin{array}{lll}1.34 & 0.21 \quad 9.8 \%\end{array}$

$25.9 \%$

Heterogeneity: $\mathrm{Chi}^{2}=13.39, \mathrm{df}=3(\mathrm{P}=0.004) ; \mathrm{I}^{2}=78 \%$

Test for overall effect: $Z=8.25(P<0.00001)$

Total $(95 \% \mathrm{Cl})$

$100.0 \% \quad 3.09[2.71,3.51]$

Heterogeneity: $\mathrm{Chi}^{2}=85.92, \mathrm{df}=28(\mathrm{P}<0.00001) ; \mathrm{I}^{2}=67 \%$

Test for overall effect: $Z=17.14(P<0.00001)$

Test for subgroup differences: $\mathrm{Chi}^{2}=31.74, \mathrm{df}=7(\mathrm{P}<0.0001), \mathrm{I}^{2}=77.9 \%$

$4.18[1.91,9.15]$ $4.62[2.52,8.48]$

$1.52[0.99,2.34]$

$3.82[2.53,5.76]$ $2.90[2.25,3.74]$

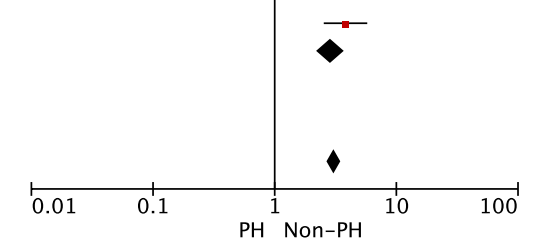

Fig. 5 Forest plot of subgroup analysis on $\mathrm{PH}$ for predicting post-stroke mortality 

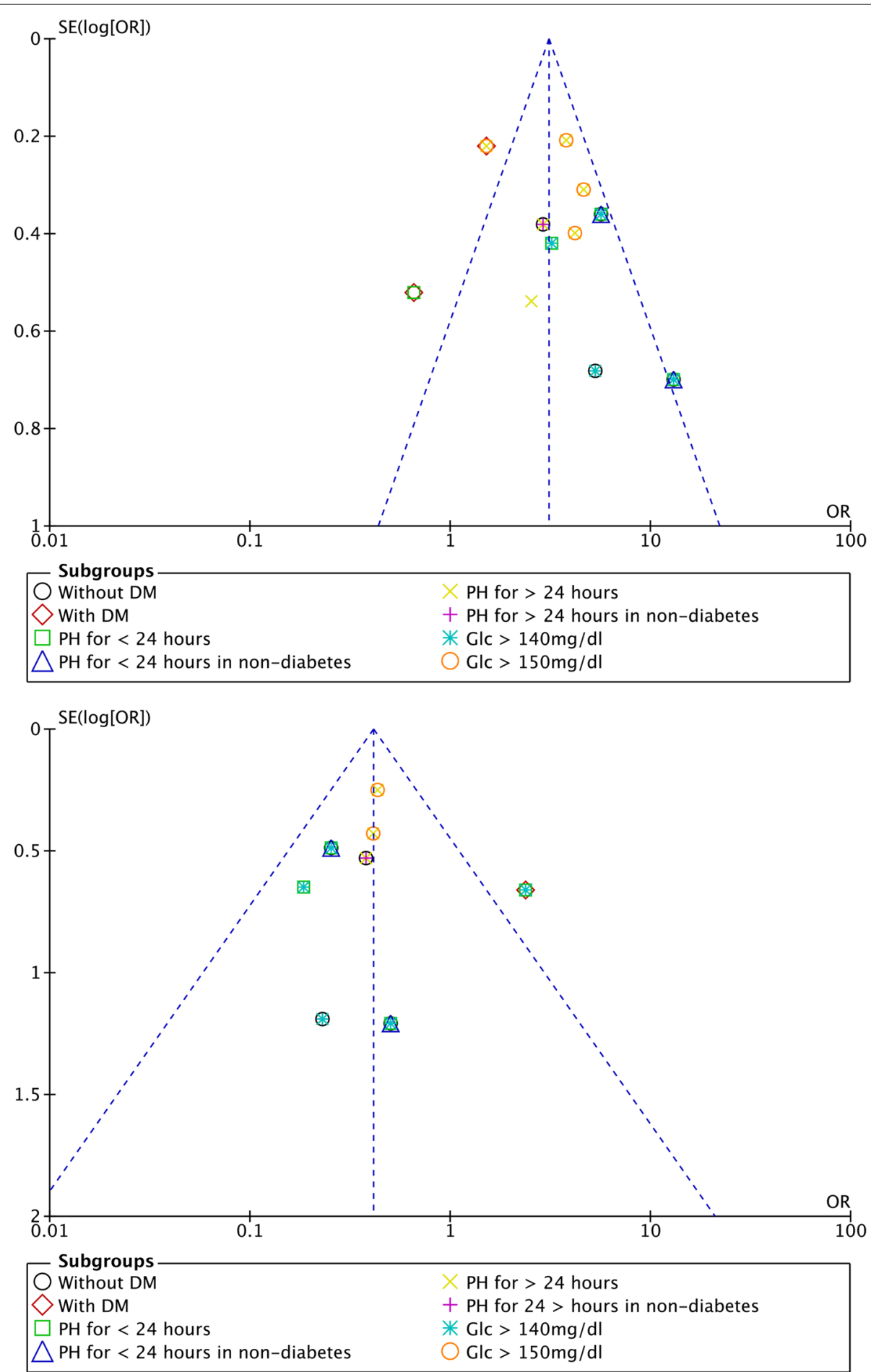

Fig. 6 Funnel plots of the subgroup analysis of $\mathrm{PH}$ and non-PH (upper), and $\mathrm{AH}$ and $\mathrm{PH}$ (lower) for post-stroke mortality

scores and $\mathrm{PH}[8,11,12,14,20,21]$, but the outcome was mostly worse in patients with $\mathrm{PH}$. Most of the studies removed the effect of disease severity in the final multivariable analysis $[8,11,12,20,21]$; therefore, the effect of disease severity on disease prognosis was not decisive or significant.

$\mathrm{SH}$ and SPH differ in the context of this study. In general, $\mathrm{SH}$ is defined as the presence of hyperglycemia at a 
random time point within $24 \mathrm{~h}$ of stroke, whereas $\mathrm{SPH}$ is a subgroup based on $\mathrm{PH}$. A persistent hyperglycemic state is theoretically a state of high blood glucose that persists over a certain period and is present at every time point during a given period. In the real world, however, a persistent hyperglycemic state is often defined by the results of two tests: a hyperglycemic state on admission to the hospital and a hyperglycemic state at a certain moment (this one moment is randomly chosen) within approximately $24 \mathrm{~h}$ or $24-48 \mathrm{~h}$ or $72 \mathrm{~h}$, or longer after admission $[8,9]$. The definition of $\mathrm{PH}$ varies between studies because of the different "real-world contexts" in which they were conducted, such as geography, but essentially, it is the detection of the hyperglycemic state at two or more random moments.

A clear definition of $\mathrm{PH}$ in the non-diabetic population is still under debate, and a couple of studies proposed that the possible definition may be a persistent (more than $24 \mathrm{~h}$ ) pathological condition with GLC $>140 \mathrm{mg} / \mathrm{dl}$ that is not due to chronic insulinopenia or chronic insulin resistance $[37,38]$. The duration differs among studies; some studies defined $24 \mathrm{~h}$ as the persistent state [9, 14] and others defined $24-48 \mathrm{~h}$ or $24-72 \mathrm{~h}$ [8], or more than 3 days. The difference in the definition of the persistent state resulted in inconsistent conclusions in the abovementioned studies. The longer the duration of the persistent state, the more negative the results [11].

Our unpublished data (Hou et al.) focused on patients with severe stroke defined by an NIHSS score $>10$, and we found that patients with a hyperglycemic status could last for 2 or even 3 weeks during the 1-month followup period. Surprisingly, persistent hyperglycemic status was unable to independently predict 1 -month mortality (see Supplemental materials Table S1-S5, Hou et al., and Table 1). Unfortunately, this study did not include a subgroup analysis of patients with and without diabetes, which might be a confounding factor.

Therefore, as far as the present conclusion is concerned, $\mathrm{PH}$ lasting for $24 \mathrm{~h}$ is perhaps the best predictor of poor prognosis in stroke patients without DM.

Our study had several limitations. First, only a small number of studies were included in the meta-analysis, which may have led to selection bias. Second, there were relatively few subgroup analyses, which did not include factors such as country, gender, and age, which might result in heterogeneity. Third, the pooled studies differed in the inclusion and exclusion criteria, the definition of hyperglycemia, short-term outcomes, and concomitant treatments. The relative risks included in the meta-analysis were not adjusted for other prognostic factors, and most published studies were included.

\section{Conclusions}

$\mathrm{PH}$, especially $\mathrm{SPH}$, can predict post-stroke mortality in non-diabetic patients. The efficacy of glycemic patterns in predicting poor stroke outcomes in non-diabetic patients was ranked as $\mathrm{SPH}>\mathrm{LPH}>\mathrm{AH}>\mathrm{PN}$. The findings of this study indicate that random blood glucose levels should be controlled to below $140 \mathrm{mg} / \mathrm{dl}$ within $24 \mathrm{~h}$ for patients with acute ischemic stroke without type 2 diabetes and with admission hyperglycemia. Preventing persistent hyperglycemia $(>24 \mathrm{~h}$ ) may reduce short-term mortality.

\section{Abbreviations \\ PH: Persistent hyperglycemia; AH: Admission hyperglycemia; SH: Short- duration hyperglycemia; PN: Persistent normoglycemia; OR: Odds ratio; NIHSS: National Institutes of Health Stroke Scale; DM: Diabetes mellitus; HT: Hemor- rhagic transformation; CNKI: China National Knowledge Infrastructure; NOS: Newcastle-Ottawa Scale; AF: Atrial fibrillation; DBP: Diastolic blood pressure; TG: Triglyceride.}

\section{Supplementary Information}

The online version contains supplementary material available at https://doi. org/10.1186/s12883-021-02512-1.

\begin{abstract}
Additional file 1: Supplemental file 1. Search strategy. Table S1. Quality evaluation of included studies using the Newcastle-Ottawa Quality Assessment Scale (cohort study). Table S1. Hou et al., 2021. Baseline characteristics of the study population and bivariate comparisons between patients with favorable and unfavorable outcomes. Table S2. Hou et al., 2021. Comparisons of short-term outcomes between patients with and without persistent hyperglycemia. Table S3. Hou et al., 2021. Baseline characteristics of the study population and bivariate comparisons between short-duration and long-duration persistent hyperglycemia groups. Table S4. Hou et al., 2021. Comparisons of short-term outcomes between patients with short- and long-duration persistent hyperglycemia. Table S5. Hou et al., 2021. Comparisons of short-term outcomes between persistent hyperglycemia patients with $\mathrm{HbA} 1 \mathrm{c}<7 \%$ and $\mathrm{HbA} 1 \mathrm{c}>=7 \%$. Figure S1. Funnel plots of $\mathrm{PH}, \mathrm{AH}, \mathrm{SH}$, non-PN for predicting post-stroke mortality and post-stroke hemorrhage [from upper left to upper right $(A-B)$, middle left to middle right $(C-D, E-F)$, lower left to lower right $(\mathrm{G}-\mathrm{H})$ ]. Figure S2. egger: Egger's test results of $\mathrm{PH}$ and non-PH groups in the general population, $\mathrm{PH}$ and non- $\mathrm{PH}$ groups without $\mathrm{DM}, \mathrm{AH}$ and $\mathrm{PH}$ groups without DM, and $\mathrm{AH}$ and $\mathrm{PN}$ groups without DM for predicting post-stroke mortality. Figure S3. Forest plot of $\mathrm{PH}$ and non-PH for predicting mortality in patients with ischemic stroke. Figure $\mathbf{S 4}$. Revised overall comparisons between $\mathrm{PH}$ and non- $\mathrm{PH}, \mathrm{AH}$ and non- $\mathrm{AH}, \mathrm{SH}$ and non- $\mathrm{SH}$, $\mathrm{PN}$ and non-PN groups (revised figure $2 \mathrm{~A}$, removed some data that may cause heterogeneity).
\end{abstract}

\section{Acknowledgments}

We thank Dr. Xiuqi Chen for the statistical analysis. We thank the patients and their families for their support and contributions to our study and other studies.

\section{Authors' contributions}

DW and $\mathrm{DH}$ designed the project. $\mathrm{DH}$ and $\mathrm{XY}$ collected the data. DH, PZ, DW, and $X Y$ analyzed the data, and DH drafted the manuscript. DW and PZ proofread and reviewed the manuscript. DH has polished the final manuscript. All authors read and approved the final manuscript.

Funding

The present study was supported by a grant from the Health Bureau of Minhang District, Shanghai (Grant No. 2020MWDXK01) in the design of the study and collection, analysis, and interpretation of data and in writing the 
manuscript and a grant from the Shanghai Fifth People's Hospital (Grant No. 2020WYZDZK04) in writing the manuscript.

\section{Availability of data and materials}

The datasets used and/or analyzed in the present study are available from the corresponding author upon reasonable request.

\section{Declarations}

\section{Ethics approval and consent to participate}

Not applicable. (Please note that our unpublished data named Hou D et al., 2021 was not prepared specifically for this meta-analysis. We included the study for analysis because it met the inclusion and exclusion assessments, and the data collection and participants enrollment were allowed by the patients and Ethical Review Board of Shanghai Fifth People's Hospital, and written informed consent was obtained from all patients or their families.)

\section{Consent for publication}

Not applicable.

\section{Competing interests}

The authors declare that they have no competing interests.

\section{Author details}

'Department of Neurology, Shanghai Fifth People's Hospital, Fudan University, 801 Heqing Road, Minhang District, Shanghai 200240, China. ${ }^{2}$ Department of Neurology, Shidong Hospital of Yangpu District, Shanghai, China. ${ }^{3}$ Department of Health Statistics, Naval Military Medical University, Shanghai, China.

\section{Received: 13 July 2021 Accepted: 6 December 2021}

Published online: 14 December 2021

\section{References}

1. Feigin VL, Norrving B, Mensah GA. Global burden of stroke. Circ Res. 2017;120(3):439-48.

2. Gattringer T, Posekany A, Niederkorn K, Knoflach M, Poltrum B, Mutzenbach $S$, et al. Predicting early mortality of acute ischemic stroke. Stroke. 2019;50(2):349-56.

3. Fuentes B, Castillo J, San Jose B, Leira R, Serena J, Vivancos J, et al. The prognostic value of capillary glucose levels in acute stroke: the GLycemia in acute stroke (GLIAS) study. Stroke. 2009;40(2):562-8.

4. Luitse MJ, van Seeters T, Horsch AD, Kool HA, Velthuis BK, Kappelle $L J$, et al. Admission hyperglycaemia and cerebral perfusion deficits in acute ischaemic stroke. Cerebrovasc Dis. 2013:35(2):163-7.

5. Lau LH, Lew J, Borschmann K, Thijs V, Ekinci El. Prevalence of diabetes and its effects on stroke outcomes: a meta-analysis and literature review. J Diab Investig. 2019;10(3):780-92.

6. Rinkel LA, Nguyen TTM, Guglielmi V, Groot AE, Posthuma L, Roos Y, et al. High admission glucose is associated with poor outcome after endovascular treatment for ischemic stroke. Stroke. 2020;51(11):3215-23.

7. Qureshi Al, Palesch YY, Martin R, Novitzke J, Cruz-Flores S, Ehtisham $A$, et al. Association of serum glucose concentrations during acute hospitalization with hematoma expansion, perihematomal edema, and three month outcome among patients with intracerebral hemorrhage. Neurocrit Care. 2011:15(3):428-35.

8. Wu TY, Putaala J, Sharma G, Strbian D, Tatlisumak T, Davis SM, et al. Persistent hyperglycemia is associated with increased mortality after Intracerebral hemorrhage. J Am Heart Assoc. 2017;6(8):1-10.

9. Merlino G, Smeralda C, Sponza M, Gigli GL, Lorenzut S, Marini A, et al. Dynamic hyperglycemic patterns predict adverse outcomes in patients with acute ischemic stroke undergoing mechanical thrombectomy. J Clin Med. 2020;9(6):1-13.

10. Yong $M$, Kaste $M$. Dynamic of hyperglycemia as a predictor of stroke outcome in the ECASS-II trial. Stroke. 2008;39(10):2749-55.

11. Ntaios G, Abatzi C, Alexandrou M, Lambrou D, Chatzopoulos S, Egli $\mathrm{M}$, et al. Persistent hyperglycemia at 24-48 $\mathrm{h}$ in acute hyperglycemic stroke patients is not associated with a worse functional outcome. Cerebrovasc Dis. 2011;32(6):561-6.
12. Fuentes B, Ortega-Casarrubios MA, Sanjose B, Castillo J, Leira R, Serena J, et al. Persistent hyperglycemia $>155 \mathrm{mg} / \mathrm{dL}$ in acute ischemic stroke patients: how well are we correcting it?: implications for outcome. Stroke. 2010;41(10):2362-5.

13. Baird TA, Parsons MW, Phan T, Butcher KS, Desmond PM, Tress BM, et al. Persistent poststroke hyperglycemia is independently associated with infarct expansion and worse clinical outcome. Stroke. 2003;34(9):2208-14.

14. Mi D, Wang P, Yang B, Pu Y, Yang Z, Liu L. Correlation of hyperglycemia with mortality after acute ischemic stroke. Ther Adv Neurol Disord. 2018;11:1756285617731686.

15. Moher D, Liberati A, Tetzlaff J, Altman DG, Group P. Preferred reporting items for systematic reviews and meta-analyses: the PRISMA statement. BMJ. 2009;339:b2535.

16. Stroup DF, Berlin JA, Morton SC, Olkin I, Williamson GD, Rennie D, et al. Meta-analysis of observational studies in EpidemiologyA proposal for reporting. JAMA. 2000;283(15):2008-12.

17. Feng W, Tauhid S, Goel S, Sidorov EV, Selim M. Hyperglycemia and outcome in intracerebral hemorrhage: from bedside to bench-more study is needed. Transl Stroke Res. 2012;3(Suppl 1):113-8.

18. Hou D, Wang C, Ye X, Zhong P, Wu D. Persistent inflammation worsens short-term outcomes in massive stroke patients. BMC Neurol. 2021;21(1):62.

19. Stang A. Critical evaluation of the Newcastle-Ottawa scale for the assessment of the quality of nonrandomized studies in meta-analyses. Eur J Epidemiol. 2010;25(9):603-5.

20. Dziedzic T, Pera J, Trabka-Janik E, Szczudlik A, Slowik A. The impact of postadmission glycemia on stroke outcome: glucose normalisation is associated with better survival. Atherosclerosis. 2010;211(2):584-8.

21. Li G, Wang C. Predictive value of hyperglycaemia in the prognosis of ischaemic cerebrovascular disease. J Shandong Univ (health science). 2010;48(4):1-4

22. Scott J, Robinson GM, French JM, O'Connell JE, Alberti KGMM, Gray CS. Prevalence of admission hyperglycaemia across clinical subtypes of acute stroke. Lancet (London, England). 1999;353:376-7.

23. Sulaiman W, Hashim HZ, Abdullah STC, Hoo FK, Basri H. Managing post stroke hyperglycaemia: moderate glycaemic control is better? An update. EXCLI J. 2014;13:825-33.

24. Kruyt ND, Nys GM, van der Worp HB, van Zandvoort MJ, Kappelle LJ, Biessels GJ. Hyperglycemia and cognitive outcome after ischemic stroke. J Neurol Sci. 2008;270(1-2):141-7.

25. Putaala J, Sairanen T, Meretoja A, Lindsberg PJ, Tiainen M, Liebkind R, et al. Post-thrombolytic hyperglycemia and 3-month outcome in acute ischemic stroke. Cerebrovasc Dis. 2011;31(1):83-92.

26. Mandava P, Martini SR, Munoz M, Dalmeida W, Sarma AK, Anderson JA, et al. Hyperglycemia worsens outcome after rt-PA primarily in the large-vessel occlusive stroke subtype. Transl Stroke Res. 2014;5(4):519-25.

27. Zewde $Y Z$, Mengesha AT, Gebreyes YF, Naess $H$. The frequency and impact of admission hyperglycemia on short term outcome of acute stroke patients admitted to Tikur Anbessa specialized hospital, Addis Ababa, Ethiopia: a cross-sectional study. BMC Neurol. 2019;19(1):342.

28. Gray CS, Hildreth AJ, Sandercock PA, O'Connell JE, Johnston DE, Cartlidge NEF, et al. Glucose-potassium-insulin infusions in the management of post-stroke hyperglycaemia: the UK glucose insulin in stroke trial (GIST-UK). Lancet Neurol. 2007;6(5):397-406.

29. Allport L, Baird T, Butcher K, Macgregor L, Prosser J, Colman P, et al. Frequency and temporal profile of poststroke hyperglycemia using continuous glucose monitoring. Diabetes Care. 2006;29(8):1839-44

30. Kruyt ND, Biessels GJ, Devries JH, Roos YB. Hyperglycemia in acute ischemic stroke: pathophysiology and clinical management. Nat Rev Neurol. 2010;6(3):145-55.

31. Capes SE, Hunt D, Malmberg K, Pathak P. Stress hyperglycemia and prognosis of stroke in nondiabetic and diabetic patients a systematic overview. Stroke. 2001;32(10):2426-32.

32. Zheng Y, Ley SH, Hu FB. Global aetiology and epidemiology of type 2 diabetes mellitus and its complications. Nat Rev Endocrinol. 2018;14(2):88-98.

33. Tziomalos K, Dimitriou P, Bouziana SD, Spanou M, Kostaki S, Angelopoulou SM, et al. Stress hyperglycemia and acute ischemic stroke in-hospital outcome. Metabolism. 2017;67:99-105. 
34. Scheen AJ. Central nervous system: a conductor orchestrating metabolic regulations harmed by both hyperglycaemia and hypoglycaemia. Diabetes Metab. 2010;36:S31-8.

35. Mergenthaler $P$, Lindauer $U$, Dienel GA, Meisel A. Sugar for the brain: the role of glucose in physiological and pathological brain function. Trends Neurosci. 2013;36(10):587-97.

36. Mergenthaler P, Kahl A, Kamitz A, van Laak V, Stohlmann K, Thomsen S, et al. Mitochondrial hexokinase II (HKII) and phosphoprotein enriched in astrocytes (PEA15) form a molecular switch governing cellular fate depending on the metabolic state. Proc Natl Acad Sci U S A. 2012;109(5):1518-23.

37. Fattorusso V, Nugnes R, Casertano A, Valerio G, Mozzillo E, Franzese A. Non-diabetic hyperglycemia in the pediatric age: why, how, and when to treat? Curr Diab Rep. 2018;18(12):140.

38. Faustino EV, Apkon M. Persistent hyperglycemia in critically ill children. J Pediatr. 2005:146(1):30-4

\section{Publisher's Note}

Springer Nature remains neutral with regard to jurisdictional claims in published maps and institutional affiliations.

- fast, convenient online submission

- thorough peer review by experienced researchers in your field

- rapid publication on acceptance

- support for research data, including large and complex data types

- gold Open Access which fosters wider collaboration and increased citations

- maximum visibility for your research: over 100M website views per year

At BMC, research is always in progress.

Learn more biomedcentral.com/submissions 